\title{
JOURNAL OF APPLIED PROBABILITY VOLUME 44 (2007): INDEX
}

Abraham, R., Dhersin, J. S. ANd Ycart, B. Strong convergence for urn models with reducible

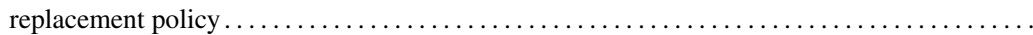

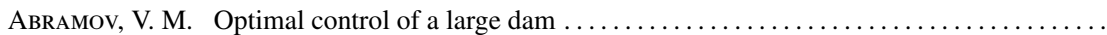

AKI, S. see Inoue, K.

AlPERn, S. Rendezvous search with revealed information: applications to the line ...........

Alsmeyer, G. And Meiners, M. A stochastic maximin fixed-point equation related to game tree evaluation. .

$652-660$

249-258

Ayesta, U. A unifying conservation law for single-server queues $\ldots \ldots \ldots \ldots \ldots \ldots \ldots \ldots \ldots$

Baldi Antognini, A. And Giannerini, S. Generalized Pólya urn designs with null balance .....

Ball, F., O’Neill, P. D. And Pike, J. Stochastic epidemic models in structured populations featuring

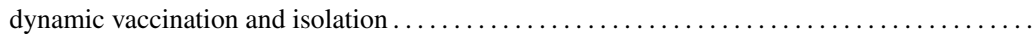

Ballani, F., Stoyan, D. and Wolf, S. On two damage accumulation models and their size effects

BANSAYE, V. On a model for the storage of files on a hardware. II. Evolution of a typical data block

Barbe, Ph., McCormick, W. P. and Zhang, C. Asymptotic expansions for distributions of compound sums of random variables with rapidly varying subexponential distribution ......

Belzunce, F., Martínez-Puertas, H. and Ruiz, J. M. Reserved preservation properties for series

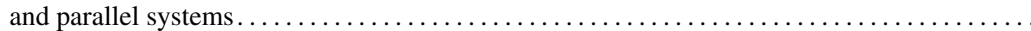

Ben Alaya, M. And Jourdain, B. Probabilistic approximation of a nonlinear parabolic equation

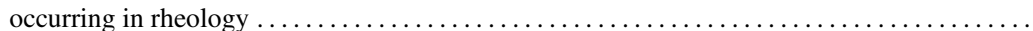

Bompadre, A., Dror, M. AND Orlin, J. B. Probabilistic analysis of unit-demand vehicle routing problems

Booth, H. S. see Kantorovitz, M. R.

Brockwell, P. J., Davis, R. A. AND YANG, Y. Estimation for nonnegative Lévy-driven Ornstein-

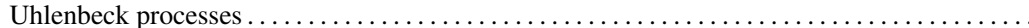

Burden, C. J. see Kantorovitz, M. R.

Cairns, B. J. see Pollett, P.

CARpio, K. J. E. AND Daley, D. J. Long-range dependence of Markov chains in discrete time on countable state space

CHA, J. H. AND Mi, J. Study of a stochastic failure model in a random environment ............

Chen, A., Pollett, P., Li, J. And Zhang, H. A remark on the uniqueness of weighted Markov branching processes

Chen, R. see Grigorescu, I.

Cheung, K. C. Characterizations of conditional comonotonicity $\ldots \ldots \ldots \ldots \ldots \ldots \ldots \ldots \ldots \ldots$

Clark, S. P. And Kiessler, P. C. A diffusion approximation for Markov renewal processes ......

Czado, C. see Haug, S.

DAley, D. J. see CARPIO, K. J. E.

DAvis, R. A. see BrockWell, P. J.

DENISOV, D. AND ZwART, B. On a theorem of Breiman and a class of random difference equations

DHERSin, J. S. see AbrahaM, R.

Dror, M. see Bompadre, A.

Dupuis, P., Nuzman, C. AND Whiting, P. Large deviation principle for occupancy problems with colored balls

Elshamy, M. A stability property of stochastic vibration

Eryilmaz, S. see NaVARro, J. 
FenG, S. AND WANG, F.-Y. A class of infinite-dimensional diffusion processes with connection to

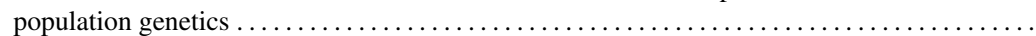

Filliger, R. AND Hongler, M.-O. Explicit Gittins indices for a class of superdiffusive processes .

FInKELSTEIN, M. On some ageing properties of general repair processes $\ldots \ldots \ldots \ldots \ldots \ldots \ldots$.

Finlay, R. AND SENETA, E. A gamma activity time process with noninteger parameter and self-similar limit.

FRANKE, B. A Lévy process whose jumps are dragged by a spherical dynamical system . . . . . . .

FreIXAS, J. Bounds for Owen's multilinear extension $\ldots \ldots \ldots \ldots \ldots \ldots \ldots \ldots \ldots \ldots \ldots \ldots \ldots$

GAPEEV, P. V. Discounted optimal stopping for maxima of some jump-diffusion processes........

Giannerini, S. see Baldi Antognini, A.

Gnedin, A. V. Optimal stopping with rank-dependent loss $\ldots \ldots \ldots \ldots \ldots \ldots \ldots \ldots \ldots \ldots$ AND MiretskiY, D. I. Winning rate in the full-information best choice problem ............

GRIGORESCU, I., CHEN, R. AND SHEPP, L. Optimal strategy for the Vardi casino with interest payments

Guillemin, F. M., Mazumdar, R. R., Rosenberg, C. P. and Ying, Y. A stochastic ordering property for leaky bucket regulated flows in packet networks $\ldots \ldots \ldots \ldots \ldots \ldots \ldots \ldots$.

Hansen, J., Reynolds, C. AND Zachary, S. Stability of processor sharing networks with

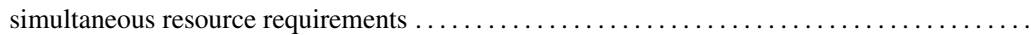

Haug, S. and Czado, C. An exponential continuous-time GARCH process . ...............

HE, X. AND Hu, Y. Ruin probability for the integrated Gaussian process with force of interest.....

HoLst, L. Counts of failure strings in certain Bernoulli sequences . . . . . . . . . . . . . . . . . see LINDELL, A.

Hongler, M.-O. see Filliger, R.

Hu, Y. AND ØKSENDAL, B. Optimal smooth portfolio selection for an insider .

$950-959$

$732-741$

$852-864$

$713-731$

996-1011

$560-565$

$199-211$

$332-348$

636-651

960-976

685-694

$824-830$

- see $\mathrm{HE}, \mathrm{X}$.

IBRAGIMov, R. Thou shall not diversify: why 'two of every sort'? . .

$742-752$

$58-70$

INOUE, K. AND AKI, S. On generating functions of waiting times and numbers of occurrences of

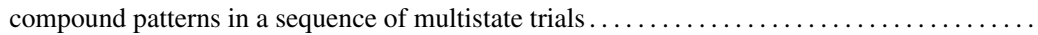

Ivanov, R. V. On the pricing of American options in exponential Lévy markets...............

Jourdain, B. see Ben Alaya, M.

Kantorovitz, M. R., Booth, H. S., Burden, C. J. and Wilson, S. R. Asymptotic behavior of $k$-word matches between two uniformly distributed sequences $\ldots \ldots \ldots \ldots \ldots \ldots \ldots \ldots$

Kiessler, P. C. see Clark, S. P.

KIM, B. see KIM, J.

KIM, J., KIM, B. AND Ko, S.-S. Tail asymptotics for the queue size distribution in an M/G/1 retrial

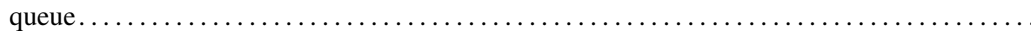

Ko, S.-S. see KIM, J.

KolesniK, A. D. A note on planar random motion at finite speed $\ldots \ldots \ldots \ldots \ldots \ldots \ldots \ldots \ldots$

Kyprianou, A. E. and Palmowski, Z. Distributional study of De Finetti's dividend problem for a general Lévy insurance risk process

LANCHIER, N. AND Neuhauser, C. Voter model and biased voter model in heterogeneous

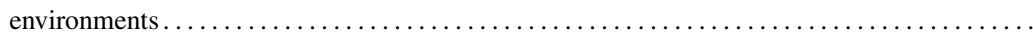

LeIPUS, R. AND SuRgailis, D. On long-range dependence in regenerative processes based on a

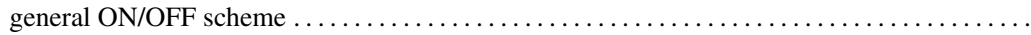

LELARGE, M. Tail asymptotics for monotone-separable networks $\ldots \ldots \ldots \ldots \ldots \ldots \ldots \ldots \ldots$

LI, J. see CHEN, A.

LI, Y. see BLOCK, H. W.

Lindell, A. AND Holst, L. Distributions of the longest excursions in a tied down simple random

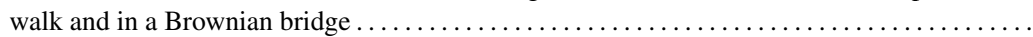

Lippman, S. A., Ross, S. M. And SeShadri, S. A weakest link marked stopping problem.........

LU, Y. AND RADOVANOVIĆ, A. Asymptotic blocking probabilities in loss networks with subexponential

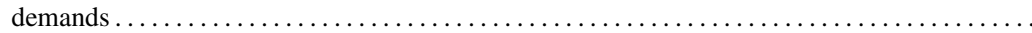

MARKSTRÖM, K. Negative association does not imply log-concavity of the rank sequence........

Martínez-Puertas, H. see Belzunce, F.

Mazumdar, R. R. see Guillemin, F. M.

McCormick, W. P. see Barbe, Ph.

Meiners, M. see Alsmeyer, G.

Mi, J. see CHA, J. H. 
Miretskiy, D. I. see Gnedin, A. V.

Molina, M., Mota, M. and Ramos, A. Some contributions to the theory of near-critical bisexual

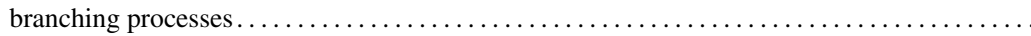

Mota, M. see Molina, M.

Nagaev, S. V. And Wachtel, V. The critical Galton-Watson process without further power moments

Navarro, J. ANd Eryilmaz, S. Mean residual lifetimes of consecutive- $k$-out-of- $n$ systems .......

NEAL, P. Coupling of two SIR epidemic models with variable susceptibilities and infectivities ....

Neuhauser, C. see Lanchier, N.

Nuzman, C. see Dupuis, P.

Oertel, F. And Owen, M. On utility-based superreplication prices of contingent claims with unbounded payoffs

ØKSENDAL, B. see $\mathrm{Hu}, \mathrm{Y}$.

O’Neill, P. D. see BALl, F.

OrLin, J. B. see Bompadre, A.

OtT, T. J. AND Swanson, J. Asymptotic behavior of a generalized TCP congestion avoidance

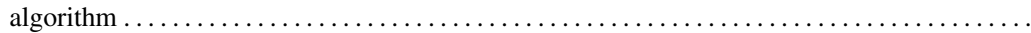

OWen, M. see Oertel, F.

Pakes, A. G. Convolution equivalence and infinite divisibility: corrections and corollaries........

PALMOWSKI, Z. AND ZWART, B. Tail asymptotics for the supremum of a regenerative process ..... see KYPRIANOU, A. E.

Pellerey, F. Comparison results for branching processes in random environments

Pievatolo, A. The downtime distribution after a failure of a system with multistate independent

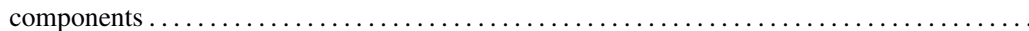

Pike, J. see BALL, F.

Pitts, S. M. AND Politis, K. The joint density of the surplus before and after ruin in the Sparre

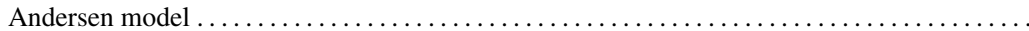

Politis, K. see Pitts, S. M.

Pollett, P., Zhang, H. ANd Cairns, B. J. A note on extinction times for the general birth, death

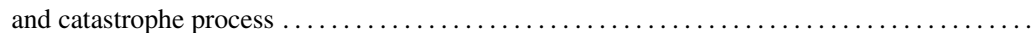
see CHEN, A. and SIRL, D.

Pontiggia, L. Nonconstant sum red-and-black games with bet-dependent win probability function

Prince, T. AND Weber, N. Fixation in conditional branching process models in population genetics

Privault, N. AND WeI, X. Integration by parts for point processes and Monte Carlo estimation ...

Radovanović, A. see Lu, Y.

Ramos, A. see Molina, M.

RENAUd, J.-F. AND Zhou, X. Distribution of the present value of dividend payments in a Lévy risk model .

REYNOLDS, C. see HANSEN, J.

Roberts, G. O. And Rosenthal, J. S. Coupling and ergodicity of adaptive Markov chain Monte

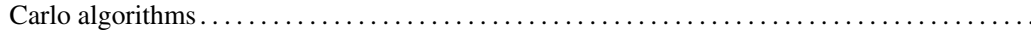

Rosenberg, C. P. see Guillemin, F. M.

Rosenthal, J. S. see Roberts, G. O.

Ross, S. M. see Lippman, S. A.

Rossignol, R. Arbitrary threshold widths for monotone, symmetric properties . . .

Ruiz, J. M. see Belzunce, F.

SAvits, T. H. see Block, H. W.

SCHIED, A. AND STAdje, M. Robustness of delta hedging for path-dependent options in local volatility

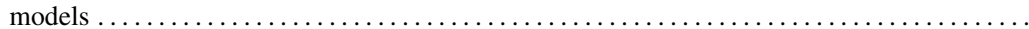

Seneta, E. see Finlay, R.

SESHADRI, S. see LIPPMAN, S. A.

ShePp, L. see Grigorescu, I.

Sirl, D., Zhang, H. ANd Pollett, P. Computable bounds for the decay parameter of a birth-death

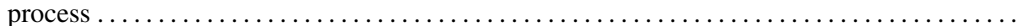

SLY, A. Integrated fractional white noise as an alternative to multifractional Brownian motion ....

Spouge, J. L. Markov additive processes and repeats in sequences (Correction: pp. 1122).......

Stadje, M. see Schied, A. 
Stoyan, D. see BALlani, F.

Surgailis, D. see LeIPus, R.

Swanson, J. see OTt, T. J.

TANG, Q. Heavy tails of discounted aggregate claims in the continuous-time renewal model ......

TsitsiashviLi, G. S. Moments of random allocation processes reaching a boundary ............

VILLENEUVE, S. On threshold strategies and the smooth-fit principle for optimal stopping problems

WACHTEL, V. see NAGAEV, S. V.

WANG, F.-Y. see FENG, S.

WANG, J. see BLOCK, H. W.

WANG, S. AND WANG, W. Precise large deviations for sums of random variables with consistently varying tails in multi-risk models

WANG, W. see WANG, S.

Weber, N. see Prince, T.

Weber, S. Distribution-invariant risk measures, entropy, and large deviations

Wei, X. see Privault, N.

Whiting, P. see Dupuis, P.

Wilson, S. R. see KANTOROVITZ, M. R.

Wolf, S. see Ballani, F.

Wu, B. AND ZHANG, Y.-H. A class of multidimensional $Q$-processes $\ldots \ldots \ldots \ldots \ldots \ldots \ldots \ldots \ldots$

YANG, Y. see BROCKWELL, P. J.

YAO, Y.-C. Explicit optimal strategy for the Vardi casino with limited playing time playing times

YcART, B. see ABraham, R.

YE, H.-Q. A paradox for admission control of multiclass queueing network with differentiated service Ying, Y. see Guillemin, F. M.

ZACHARY, S. A note on insensitivity in stochastic networks . see HANSEN, J.

Zhang, C. see BARbe, Ph.

Zhang, H. see Chen, A., Pollett, P. and Sirl, D.

ZHANG, Y.-H. see Wu, B.

ZHOU, X. Exit problems for spectrally negative Lévy process reflected at either the supremum or the

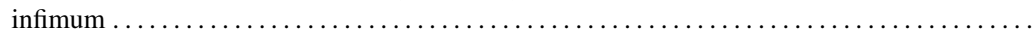
see RENAUD, J.-F.

Zwart, B. see Denisov, D. and PALmowski, Z. 